\title{
A Survey on Electrical Energy Storage Potential in South- East Europe to Support Transmission Network Flexibility
}

DOI:

2018 IEEE PES Innovative Smart Grid Technologies Conference Europe (ISGT-Europe)

\section{Document Version}

Accepted author manuscript

Link to publication record in Manchester Research Explorer

\section{Citation for published version (APA):}

Hasan, K., Wang, M., Adrees, A., \& Milanovic, J. V. (2018). A Survey on Electrical Energy Storage Potential in South-East Europe to Support Transmission Network Flexibility. In 2018 IEEE PES Innovative Smart Grid

Technologies Conference Europe (ISGT-Europe) https://doi.org/2018 IEEE PES Innovative Smart Grid

Technologies Conference Europe (ISGT-Europe)

\section{Published in:}

2018 IEEE PES Innovative Smart Grid Technologies Conference Europe (ISGT-Europe)

\section{Citing this paper}

Please note that where the full-text provided on Manchester Research Explorer is the Author Accepted Manuscript or Proof version this may differ from the final Published version. If citing, it is advised that you check and use the publisher's definitive version.

\section{General rights}

Copyright and moral rights for the publications made accessible in the Research Explorer are retained by the authors and/or other copyright owners and it is a condition of accessing publications that users recognise and abide by the legal requirements associated with these rights.

\section{Takedown policy}

If you believe that this document breaches copyright please refer to the University of Manchester's Takedown Procedures [http://man.ac.uk/04Y6Bo] or contact uml.scholarlycommunications@manchester.ac.uk providing relevant details, so we can investigate your claim.

\section{OPEN ACCESS}




\title{
A Survey on Electrical Energy Storage Potential in South-East Europe to Support Transmission Network Flexibility
}

\author{
Kazi N. Hasan, Mengxuan Wang, Atia Adrees, and Jovica V. Milanović \\ School of Electrical and Electronic Engineering \\ The University of Manchester \\ Manchester, United Kingdom \\ \{kazi.hasan, mengxuan.wang, atia.adrees, milanovic\}@ manchester.ac.uk
}

\begin{abstract}
Electrical Energy Storage (EES) facilities have attracted a huge interest recently in increasing the operational flexibility of modern power systems. This interest is fueled by the integration of a high amount of intermittent renewable energy resources (RES) in the networks. This study has been performed to analyze and identify the potential of EES in providing the operational flexibility of power networks in 8 South-East European countries. For that purpose, a survey questionnaire was developed on EES, which was distributed in late 2017 and responses were collected in January 2018. The questionnaires collected information on existing EES capacities, the required amount of EES for flexible operation and the future potential of these resources. Additional key information was collected about these resources, such as the characteristics, location and network services obtained from these resources, as well as the influential market participants to provide these services in the network. This study will facilitate the cross-border management of RES by increasing the operational flexibility of the transmission network in South-East Europe.
\end{abstract}

Index Terms-Electrical energy storage, flexibility, questionnaire, renewable energy, survey.

\section{INTRODUCTION}

The integration of a large amount of intermittent renewable energy resources (RES) adversely affects the flexibility of the operation of a power system [1]. Traditional power systems have been operated in such a way that the conventional power plants (such as base load, intermediate and peaking) are scheduled to follow system loading patterns (i.e. daily, weekly and seasonal). In such systems, the control and provision of flexibility is usually delivered by the supply side control.

The integration of a large amount of intermittent RES in the network is prohibitive to providing total control and a provision of flexibility from the supply side due to the weather dependence of RES resources. For this reason, power systems with a high share of RES are looking for options to obtain the control and provision of flexibility from electrical energy storage (EES) and the demand side [2-4].

Considering the technologies of worldwide grid connected EES, a vast majority (98\%) of this capacity is comprised of pumped hydro storage technologies. The other $2 \%$ includes a mix of battery technologies (predominantly Lithium-ion), compressed air energy storage, and flywheels [4].

In the delivery of different types of network services, particular technology type factually serves better for a specific purpose. For example, pumped hydro storage delivered mostly (about $90 \%$ of the worldwide usage) in the past to the electric energy time shift, whereas, electro-chemical (battery) storage devices are prevalent (about 50\% of the worldwide usage) for providing frequency regulation [3]. On the other hand, electromechanical storage devices are the best suited (about $55 \%$ of the worldwide usage) to provide on-site power. Furthermore, thermal storage devices are superior choice (about $70 \%$ of the worldwide usage) for renewable capacity firming [3].

The electrical energy storage (EES) resources have been installed in different parts (i.e. generation, transmission and distribution level) of the network to obtain a range of services. Such as transmission services include congestion relief and investment deferral [2, 3]. Distribution services include voltage support, loss reduction and investment deferral [2, 3]. End-use applications (i.e. at consumer-level) of EES facilitate increased reliability, power quality improvement, demand side management and respond to real time pricing [2, 3]. The ancillary services include fast-frequency response, ramping reserves, voltage support, contingency spinning reserve, and black-start capability [3-6].

There have been a number of reports produced recently on EES, which include European Commission DG Energy 2011 and 2016, IEA-RETD 2016, IRENA 2015a and 2015b, EASE /EERA 2013, and these reflect the perceived importance of ESS in the electricity network [7-10]. These references highlighted the existing operation and future roadmaps of EES in different regulatory regimes with detailed analysis of the comparison of characteristics, efficiency, life time, energy and power density, environmental impact, applications, business models, cost-benefit, obstacles and opportunities for alternative EES options.

The current study has been undertaken to estimate the provision of the potential flexibility which can be obtained from EES to facilitate a secure, reliable and economic operation of the South-East European interconnected transmission network. This survey is conducted as a part of 


\section{ACCEPTED VERSION OF THE PAPER}

the EU H2020 project CROSSBOW (CROSS-BOrder management of variable renewable energies and storage units enabling a transnational Wholesale market) [11].

The CROSSBOW project is a platform for enabling the aggregated use of RES, DSM and EES in 8 South-East European countries. The project is expected to develop a framework and algorithms that will provide a clear guidance and methodology to deploy advanced EES in order to facilitate an increased cross border power transfer at the national and transnational level, while ensuring at all times network voltage, angular and frequency stability. Moreover, it is expected to enhance the security and economy of the transnational wholesale and ancillary markets. Thus the EES resources are expected to participate in the primary, secondary, and tertiary frequency control and intraday energy markets. Furthermore, it will contribute to transmission deferral and distribution deferral services. To address these issues, CROSSBOW will investigate the effect of EES on overall network steady state and dynamic operation and cross border power exchange.

One of the initial tasks of the CROSSBOW project was to investigate and identify the potential of EES capacities in the region. The questionnaires have been developed to collect information on the EES about the existing capacities, and the required amount of EES for the flexible operation and potential future availability of these resources. Additional key information was collected about these resources, such as the characteristics, location, and network services obtained, as well as the influential market participants, to provide these resources in the network.

The major contribution of this paper is the assessment of existing EES resources available in individual countries within the South-East European interconnected transmission network. Thus this will lead to deploy advanced EES in order to facilitate an increased cross border power transfer at the national and transnational level, while ensuring network security and efficient market operation. A questionnaire was developed on EES and distributed in late 2017. The responses were collected in January 2018 from 9 operators of 8 SouthEast European countries. This paper summarizes some of the key findings of these surveys.

\section{OVERVIEW OF PAST EES SURVEYS}

A survey is usually conducted for a particular purpose and issued to a selected type of participant. The previous surveys have been conducted on EES for different purposes.

\section{A. Previous Surveys on Electrical Energy Storage (EES)}

A theoretical overview of the mechanical, electrical, electromechanical and thermal storage systems is presented in [12]. This review includes a comparison of the characteristics and properties of energy storage technologies, including power rating, life time, cost, applications, advantages and disadvantages. Another review of the battery EES technologies considering their operating characteristics is presented in [13]. This presented the mathematical models and equivalent electrical circuits for several battery EES technologies. Additional review of the EES technologies, capacities, modeling and techno-economic aspects is presented in [14].
This review includes the efficiency, power and energy density of different EES technologies. Abovementioned studies present a review of the existing technologies of EES and their characteristics, but not particularly about the existing EES resources in the network.

Nevertheless, there is no survey, to the best of our knowledge, on the EES potential at the transmission network level of the South-East European countries, which will be needed to assess the flexibility of the operation of the regional transnational wholesale electricity market. Hence, this survey is undertaken to estimate the provision of potential flexibility, through the EES resources, to facilitate the secure and economic operation of the South-East European interconnected transmission network.

\section{ELECTRICAL ENERGY STORAGE (EES) SURVEY}

This section discusses the organization of the EES questionnaire and survey participants.

\section{A. Organization of the Questionnaire}

The questionnaire was developed to identify the potential of the EES in the region. In total 12 questions were asked, as presented in Table I. The questions can be divided into the following six categories: 1) what is the existing EES capacity, 2) how much EES capacity is needed, 3) what are the preferred times for charging and discharging, 4) what are the existing and preferable EES technologies, 5) what are the preferred network services to obtain from EES, and 6) where are the EES located in the network and what are their typical characteristics.

\section{B. Survey Participants}

This survey was conducted as part of the CROSSBOW project and hence all utility partners of the CROSSBOW consortium contributed to the survey. The questionnaire was distributed over November-December 2017 and the responses

TABLE I. EES SURVEY QUESTIONS

\begin{tabular}{|c|l|}
\hline $\begin{array}{c}\text { Question } \\
\text { No. }\end{array}$ & \multicolumn{1}{c|}{ Question } \\
\hline Q1 & Representing a transmission or distribution network operator \\
\hline Q2 & Maximum and the minimum yearly demand in the network \\
\hline Q3 & $\begin{array}{l}\text { Maximum and minimum amount of renewable generation in } \\
\text { the network }\end{array}$ \\
\hline Q4 & $\begin{array}{l}\text { Total installed and required (for more flexible operation) } \\
\text { energy storage in the network }\end{array}$ \\
\hline Q5 & $\begin{array}{l}\text { Top 5 existing energy storage technologies in the network } \\
\text { that have the largest storage capacity }\end{array}$ \\
\hline Q6 & $\begin{array}{l}\text { Location in the network and the voltage level of the energy } \\
\text { storage connection }\end{array}$ \\
\hline Q7 & $\begin{array}{l}\text { Typical periods of day when the prevalent energy storage } \\
\text { devices/facilities are charging and discharging }\end{array}$ \\
\hline Q8 & $\begin{array}{l}\text { Typical charging and discharging times for the prevalent } \\
\text { energy storage devices/facilities in the network }\end{array}$ \\
\hline Q9 & $\begin{array}{l}\text { Typical response time for each type of energy storage } \\
\text { technology }\end{array}$ \\
\hline Q10 & $\begin{array}{l}\text { Top 5 services obtained over the last 12 months from the } \\
\text { energy storage devices/facilities }\end{array}$ \\
\hline Q11 & $\begin{array}{l}\text { Top 5 services to obtain from the energy storage to increase } \\
\text { flexibility of operation of the network }\end{array}$ \\
\hline Q12 & $\begin{array}{l}\text { Top 5 energy storage technologies that will be installed in } \\
\text { the network in the next 3-5 years }\end{array}$ \\
\hline
\end{tabular}




\section{ACCEPTED VERSION OF THE PAPER}

were collected in January 2018. All 9 TSOs and DSOs

responded to the survey.

\section{RESULTS OF THE EES SURVEY}

This section presents the responses to the EES survey and analyzes the response to each question separately.

\section{A. Q1: Representing a transmission or distribution network}

This question was asked to identify the respondent and their working horizon. In total 8 respondents were from the TSO and 1 from the DSO.

\section{B. Q2: Maximum and the minimum yearly demand in the network}

The response to this question is shown in Fig. 1. The amount of maximum demand gives an indication of the size of the network. The maximum demand varies from $653 \mathrm{MW}$ to 9,771 MW and minimum demand varies from $174 \mathrm{MW}$ to 4,085 MW. Maximum demand occurs in all countries during the winter season (December - February) and minimum demand occurs in the summer season (May - July). Fig. 1 shows the variations in the amount of consumption in the region between maximum and minimum demand.

\section{Q3: Maximum and minimum amount of renewable generation in the network}

The response to this question is presented in Fig. 2. The renewable energy resources (RES) is supplied by (in descending order of the capacity) hydro, PV, wind, biomass and co-gen technologies in this region, which are 58\%, 21\%, $20 \%, 1 \%$, and $0.4 \%$ of the total RES capacity in South-East Europe. The total capacity of hydro power, PV, wind, biomass, and co-gen are, 20,470 MW, 7,315 MW, 7,183 MW, 344 MW, and $143 \mathrm{MW}$, respectively.

These eight countries of the South-East Europe have total 64 GW generation capacity, $34 \mathrm{GW}$ peak loads, $12 \mathrm{GW}(18 \%$ of the total installed capacity) intermittent renewable (wind and PV) generation capacity [15]. The total intermittent renewable generation capacity in the region is $36 \%$ of the peak load. In particular, RES technologies such as Hydro, PV, wind, biomass and co-gen accounts for $49 \%, 18 \%, 17 \%, 1 \%$ and $0.35 \%$ of the maximum demand of the region, respectively.

A high amount of flexibility resources (such as EES) is required for such a system to facilitate the increased penetration of renewables. The hydro power is generated in 6 countries, wind in 6 countries, $\mathrm{PV}$ in 5 countries, biomass in 4 countries, and co-gen in one country.

D. Q4: Total installed capacity and required energy storage in the network (for more flexible operation)

Five countries out of nine have EES resource at transmission level, with the EES resources of 933, 240, 571 and $440 \mathrm{MW}$ capacities, which are 12\%, 7\%, 6\%, 20\%, and 8\% of the maximum demand of those countries, respectively. Fig. 3 shows the EES capacities and their parentage with respect to the maximum demand of the respective networks. In total, the installed capacity of the EES in the region is 2,784 MW, as shown in Fig. 4, which is $6.7 \%$ of the maximum demand of the region.

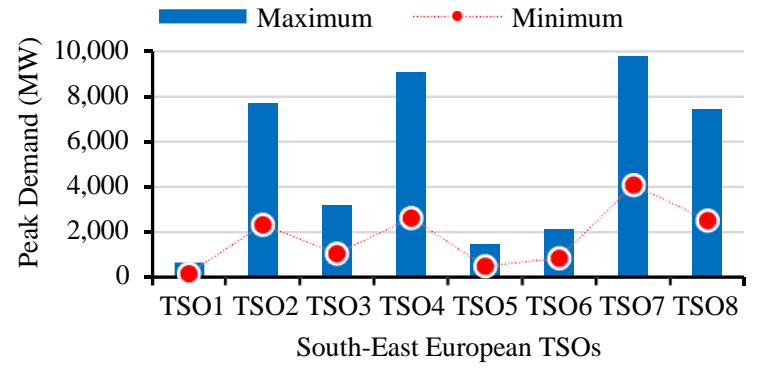

Fig. 1 EES-Q2: maximum \& minimum demand in different TSOs.

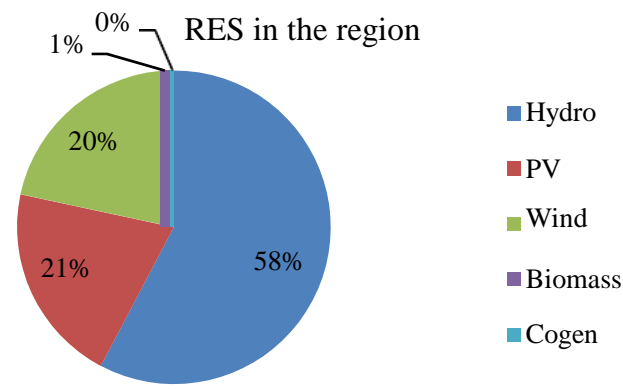

Fig. 2 EES-Q3: total RES generation capacity in the region.

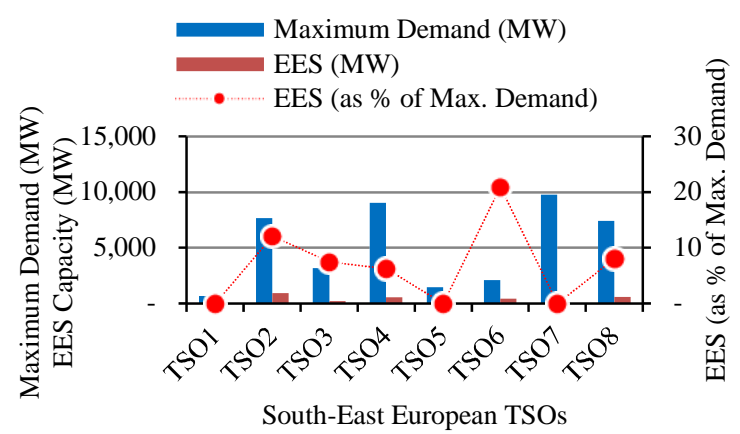

Fig. 3 EES -Q4: total available EES in the region.

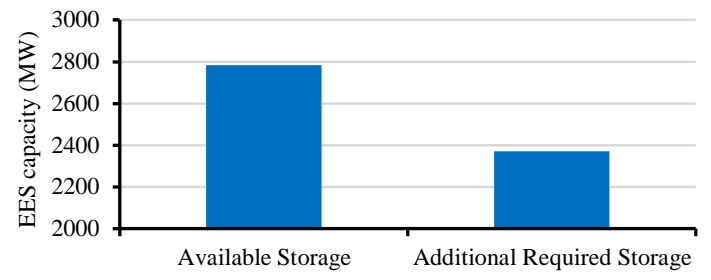

Fig. 4 EES -Q4: total available and required EES in the region.

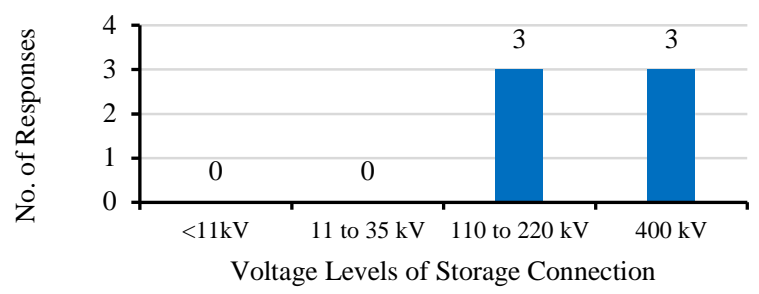

Fig. 5 EES -Q6: location of EES in the network. 


\section{ACCEPTED VERSION OF THE PAPER}

The required EES capacities in different South-East European countries have been identified. Four participants identified their EES requirements as 50, 1200, 100, and 220 MW, which is $8 \%, 16 \%, 7 \%$, and $10 \%$ of their peak load, respectively. It was identified by the TSOs that the additional amount of EES, which is required for flexible operation of the network, is 2,370 MW (as shown in Fig. 4). This will increase the EES to peak load ratio in the region from $6.7 \%$ to $11 \%$. The responses from the TSOs reveal the fact that the proportion of EES is needed to be increased in the network (to obtain their preferred services as will be explained later in Q11) and the plans and actions are in place to achieve this goal.

\section{E. Q5: Installed EES technologies with the largest storage capacity}

Existing EES technologies in the region include largely pumped hydro storage (PHS) and a negligible amount of electric vehicle (EV). Total PHS capacity in the region is 2,784 MW in 4 TSOs and EV capacity of $7.5 \mathrm{MW}$ in a single TSO. The percentage of PHS is $6.7 \%$ and $\mathrm{EV}$ in $0.02 \%$ of the maximum demand of the region.

There are 4 TSOs in the region, which do not have any EES technologies connected at the transmission network.

\section{F. Q6: The location in the network and the voltage level of the EES connection}

This question was asked to identify whether the EES are connected at the generation, transmission, distribution or customer level in the network. The locations of the EES are in the generation-site in 3 countries, at transmission level in one country. The TSOs did not provide information about the distribution level or customer operated EES in the region.

As can be seen from Fig. 5, the connected EES are at 110 to $220 \mathrm{kV}$ level in 3 countries and at $400 \mathrm{kV}$ level in 3 countries. There is no EES facility at voltage level $110 \mathrm{kV}$ and below in the transmission network.

\section{G. Q7: Typical periods of day when the prevalent EES devices/facilities are charging and discharging}

This question identifies the charging and discharging pattern of the EES technologies connected to the network. Typical charging time was identified as between 00:00 - 07:00 $(n=5)$ and 12:00 - 17:00 $(n=3)$ hours. On the other hand, typical discharging time was identified as between 18:00 23:00 $(n=4)$.

H. Q8: Typical charging and discharging duration for the prevalent EES devices/facilities in the network

Fig. 6 shows the charging and discharging duration for the EES resources connected to the network. Three participants specifically provided charging/discharging duration and two of them did not specify the time duration, except saying "hours". Four participants did not respond to this question. Charging duration varies between 5 to 7 hours and the discharging duration varies between 3 to 5 hours. This question is complimentary to the Q7 above.

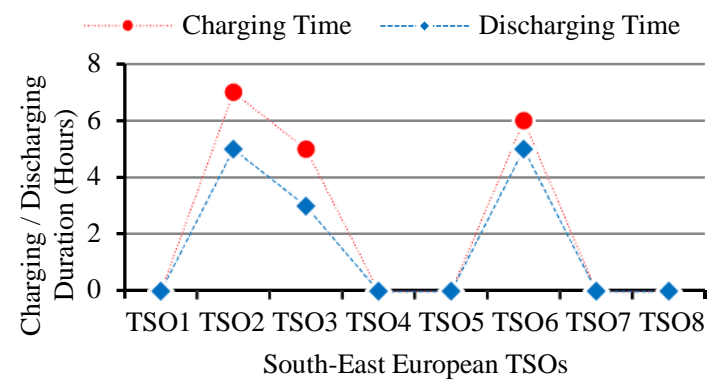

Fig. 6 EES -Q8: charging/discharging duration for EES devices

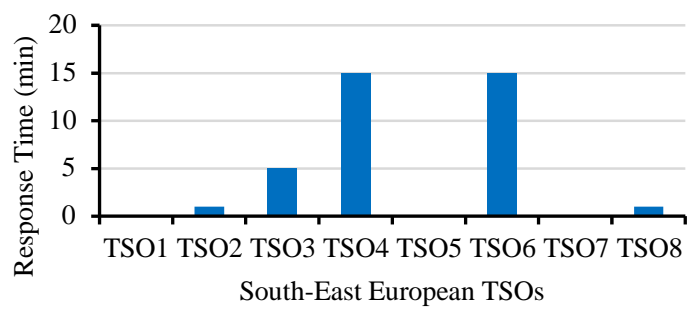

Fig. 7 EES -Q9: response time for EES devices.

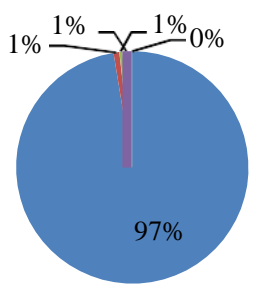

$$
\begin{aligned}
& \text { Energy trading } \\
& \text { - Frequency response } \\
& \text { Peak Shaving } \\
& \text { - Area regulation } \\
& \text { Transmission } \\
& \text { congestion relief }
\end{aligned}
$$

Fig. 8 EES -Q10: services got from EES over the last 12 months.

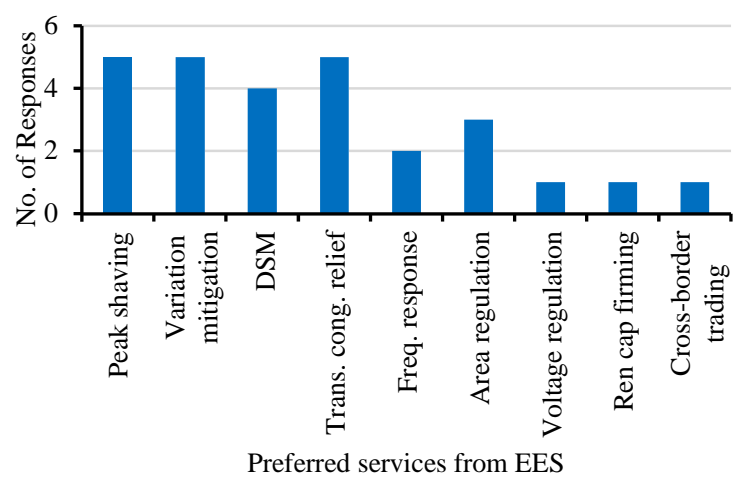

Fig. 9 EES -Q11: top-rated services to obtain from EES.

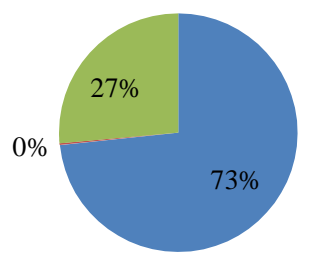

- Pumped Hydro

- Battery

Electric Vehicle

Fig. 10 EES -Q12: top-rated EES to be installed in 3 5 years. 


\section{ACCEPTED VERSION OF THE PAPER}

\section{Q9: Typical response time for each type of EES technology}

This question identifies how fast the EES is able to respond to voltage and frequency variations and start supporting the network. As can be seen from Fig. 7, two TSOs have the capability to provide EES operation in 1 minute, one TSO in 5 minutes, and two other TSOs are in 15 minutes. Three TSOs did not respond to this question.

\section{J. Q10: Top five services obtained from the existing EES devices/facilities over the last 12 months}

Fig. 8 shows the network services obtained from the EES devices over the last 12 months. As can be seen from Fig. 8, the largest proportion of services from EES goes for energy trading, which is more than $97 \%$ of the total service. Other network services obtained from EES are frequency response, peak shaving, area regulation and transmission congestion relief. There are some other network services such as voltage regulation, mitigation of variation, and reserve capacity, which have been obtained by EES, but the relevent caapcity has not been provided by the TSOs.

In terms of the number of TSOs, that are getting different network services from EES over the last 12 months, they are as follows: area regulation $(n=3)$, frequency response $(n=2)$, voltage regulation $(n=2)$, peak shaving $(n=2)$, energy trading $(n=2)$, mitigation of variation $(n=1)$, transmission congestion relief $(n=1)$ and reserve capacity $(n=1)$.

\section{K. Q11: Top five services to obtain from the EES to increase} flexibility of operation of the network

This question identifies the aspirational targets of surveyed utilities in obtaining the desired network services from the EES Fig. 9 shows that the most required network services are peak shaving, voltage mitigation and transmission congestion relief. These were identified as the services that would contribute the most to the efficient management of their network.

\section{Q12: Top five EES technologies that will be installed in the network within the next 3-5 years}

Fig. 10 shows the EES technologies, which will be installed in the region within next 3-5 years. As can be seen from Fig. 10 , these technologies are pumped hydro storage, battery and electric vehicle, with the estimated installed capacity of 1663,5 and $600 \mathrm{MW}$, respectively, or $73 \%, 0.22 \%$ and $26.5 \%$, respectively, of the total planned capacity of EES.

\section{CONCLUSIONS}

This paper presents a summary of the results of a survey on the estimation of the existing and potential use of electrical energy storage. The survey was conducted, at this stage, for the South-East European countries to facilitate the operational flexibility of power networks by improving the cross-border management of variable renewable energies and storage units enabling a transnational wholesale market.

The survey was conducted to identify the following major aspects of the EES in the region: 1) what is the existing EES capacity, 2) how much EES capacity is needed, 3) what are the potential providers/technologies for EES, and 4) what network services could be provided by (or expected to obtain from) the EES services.
The survey indicates that there is a lack of EES facilities in the region relative to the total electricity generation capacity and consumption, and intermittent renewable energy capacity. The region has a total $64 \mathrm{GW}$ generation capacity, $34 \mathrm{GW}$ peak loads, $12 \mathrm{GW}$ (18\% of the total installed capacity) intermittent renewable (wind and PV) generation capacity. The total intermittent renewable generation capacity in the region is $36 \%$ of the peak load. Hence, a high amount of flexibility resources (such as EES) is required for such a system to facilitate the increased penetration of renewables.

The total EES capacity in the region however is only $6.7 \%$ of the peak load. The EES is not distributed uniformly across the region though. Four out of nine countries have EES resource at transmission level with capacities of 12\%, 7\%, 6\% and $20 \%$ of the peak load. In total, existing EES resources include $2.18 \mathrm{GW}$ pumped hydro generation and 7.5 MW electric vehicles. The cumulative pumped hydro capacity of 9 countries is $2.18 \mathrm{GW}$, which is significantly lower compared to some other countries in Europe, such as Italy $9 \mathrm{GW}$, Germany 7.4 GW, Spain 6.8 GW, France 5.3 GW, Austria 4.7 GW and UK 3.2 GW [16].

The survey also identified the required EES capacity in the region. Four participants identified their EES requirements as $50,1200,100$, and $220 \mathrm{MW}$, which is $8 \%, 16 \%, 7 \%$, and $10 \%$ of their peak load, respectively. If materialize, this would increase the EES to peak load ratio in the region from $6.7 \%$ to $11 \%$.

The potential EES technologies to be installed in the region over the next 3 to 5 years have been identified as pumped hydro storage $(1,663 \mathrm{MW})$, battery $(5 \mathrm{MW})$ and electric vehicle (599 MW), representing $73 \%, 0.22 \%$ and $26.5 \%$ of the total planned capacity of EES. In terms of the percentage of maximum demand, that is $4.02 \%, 0.01 \%$ and $1.45 \%$, for the PHS, battery and EV, respectively.

The network services, that the utilities would like to obtain from the EES include frequency response, voltage regulation, area regulation, peak shaving, mitigation of variation, energy trading, and reserve capacity.

The results of this survey contributed to estimate both, the existing use of EES and the EES potential in the region. They will inform the development of regulatory and technological framework for advanced application of EES to facilitate crossborder power transfer and increase renewable energy penetration in the electricity grid in the region while ensuring the appropriate voltage and frequency profile and maximum benefit to the network.

\section{ACKNOWLEDGMENT AND DISCLAIMER}

The authors would like to acknowledge the support of colleagues from the utilities and system operators, who took part in the survey to respond to the questionnaire and kindly shared their knowledge and experience.

This research is supported by the EU H2020 project CROSSBOW ( Grant Agreement no. 773430).

This paper reflects only the author's views and neither the Agency nor the Commission are responsible for any use that may be made of the information contained therein. 


\section{ACCEPTED VERSION OF THE PAPER}

\section{REFERENCES}

[1] California ISO, "Integration of Renewable Resources at $20 \%$ RPS", Aug 2010. http://www.caiso.com/Documents/ Integration-RenewableResources-OperationalRequirementsand GenerationFleetCapabilityAt20PercRPS.pdf

[2] D. Stenclik, P. Denholm, and B. Chalamala, "Maintaining Balance: The Increasing Role of Energy Storage for Renewable Integration," IEEE Power and Energy Magazine, vol. 15, no. 6, pp. 31-39, 2017.

[3] IRENA, "Electricity storage and renewables: costs and markets to 2030", October 2017. http://www.irena.org/-/media/Files/ IRENA/Agency/Publication/2017/Oct/IRENA_Electricity_Stora ge_Costs_2017.pdf

[4] EPRI, "Electricity Energy Storage Technology Options - A White Paper Primer on Applications, Costs and Benefits", Palo Alto, California, 2010.

[5] G. Strbac et. al., "Value of Flexibility in a Decarbonised Grid and System Externalities of Low-Carbon Generation Technologies." https://documents.theccc.org.uk/wp-content/ uploads/2015/10/CCC_Externalities_report_Imperial_Final_21 Oct20151.pdf

[6] H. Chen, T. N. Cong, W. Yang, C. Tan, Y. Li, and Y. Ding, "Progress in electrical energy storage system: A critical review," Progress in Natural Science, vol. 19, no. 3, pp. 291-312, March 2009.

[7] European Commission, "Energy Storage - Proposed policy principles and definition". 2016. https://ec.europa.eu/energy/ sites/ener/files/documents/Proposed\%20definition $\% 20$ and $\% 20 \mathrm{p}$ rinciples\%20for\%20energy\%20storage.pdf
[8] IEA-RETD, "Policies for Storing Renewable Energy - A Scoping Study of Policy Considerations for Energy Storage (RESTORAGE)", March 2016.

[9] IRENA, "Battery Storage for Renewables: Market Status and Technology Outlook", January 2015. http://www.irena.org/ documentdownloads/publications/irena_battery_storage_report_ 2015.pdf

[10] IRENA, "Renewables and electricity storage a technology roadmap for 2030", June 2015. https://www.irena.org/Document Downloads/ Publications/ IRENA_REmap_Electricity_Storage_2015.pdf

[11] CROSSBOW. [available] http://crossbowproject.eu/

[12] Dekka, R. Ghaffari, B. Venkatesh, and W. Bin, "A survey on energy storage technologies in power systems," in 2015 IEEE Electrical Power and Energy Conference (EPEC), 2015, pp. 105-111.

[13] R. Sparacino, G. F. Reed, R. J. Kerestes, B. M. Grainger, and Z. T. Smith, "Survey of battery energy storage systems and modeling techniques," in 2012 IEEE Power and Energy Society General Meeting, 2012, pp. 1-8.

[14] S. Hameer and J. Van Niekerk, "A review of large-scale electrical energy storage", International Journal of Energy Research, vol. 39, 2015, pp1179-1195.

[15] ENTSOE. ENTSO-E Transparency Platform. Accessed March 2018. Available: https://transparency.entsoe.eu/

[16] European Commission, "The future role and challenges of energy storage". Accessed on 29/05/2018. https://ec.europa.eu/ energy/sites/ener/files/energy_storage.pdf 